\title{
Modeling and Performance Analysis for Low Altitude Electric UAVs
}

\author{
Guangtong $\mathrm{Xu}^{1, \mathrm{a}}$, Li $\mathrm{Liu}^{2, \mathrm{~b}}$ and Xiaohui Zhang ${ }^{3, \mathrm{c}}$ \\ ${ }^{1}$ Beijing Institute of Technology, Beijing, China, 100081 \\ ${ }^{2}$ Beijing Institute of Technology, Beijing, China, 100081 \\ aguangtong_xu@163.com, 'liuli@bit.edu.cn, zxhatbit@gmil.com
}

Keywords: Battery; Fuel cell; Electric propulsion; Modeling and analysis

Abstract. Compared with traditional internal-combustion engine powered UAVs, electric UAVs have no emission of pollutants and low acoustic signal. So they are more suitable for military or civil missions involving intelligence, surveillance, or reconnaissance (ISR). This paper builds two electric propulsion systems powered by lithium-ion batteries and a proton exchange membrane fuel cell (PEMFC) respectively for low altitude UAVs. The power sources are built with SimPowerSystems blockset in Matlab/Simulink and the UAV model is modeled with AeroSim blockset. To validate these models, the two electric UAVs fly through a diamond flight path with four given mission waypoints. The simulation results of the two electric propulsion systems and the UAV performance, such as dynamic response and endurance, are presented and analyzed. Finally, the endurance of the Li-Ion battery and the fuel cell UAVs with the same weight are compared. And due to the high energy density of the fuel cell, the fuel cell UAV has longer endurance.

\section{Introduction}

Electric propulsion is attractive for small low altitude UAVs ${ }^{[1]}$. Compared with traditional UAVs which have internal-combustion engines or turbofan propulsions, electric UAVs are preferred by military, civil and research applications, because it has low noise, low thermal signature, relatively long endurance and no pollution performance ${ }^{[2]}$. Modeling is a vital part of conceptual design. The electric propulsion model is the key technology of electric powered UAVs. In general, electric propulsion system contains the power sources, electric motors and propellers. Nowadays, lithium-ion batteries are increasingly being used to meet the energy demand of UAVs ${ }^{[3]}$. The energy density of mature batteries, however, limits the achievable endurance of battery powered UAVs. This has promoted the application of advanced fuel-cell powered UAVs ${ }^{[4]}$. The battery allows for a direct extraction of electric power ${ }^{[5]}$. However, fuel cells convert the hydrogen energy to electric energy, so it should take time to start up ${ }^{[6]}$.

There are two main directions, which are optimization of flight path and implementing alternative energy technology e.g., fuel cells, solar cells, and hybrid propulsion system, to enhance the endurance of UAVs ${ }^{[7]}$. Ref. [8] establishes a hybrid-electric propulsion model for achieving energy efficiency onboard the UAV. However, the model mainly utilize piston engine to power UAVs. In [9] Peter and Eric describe a physically-based model for design and optimization of a fuel cell powered electric propulsion system for UAVs, but they didn't integrate the model into a complete UAV.

This paper builds a framework for the implementation and simulation of electric UAVs in the Simulink environment. The power sources models including battery and fuel cell, and the powertrain model containing a simple DCDC converter, a brushless DC motor, and a propeller are all built using SimPowerSystems blockset in Matlab/simulink. The whole UAV model, including guidance navigation and control systems is made with Aerosim blockset also in Matlab/simulink. Then the performance of battery-powered UAVs and fuel-cell powered UAVs, e.g., endurance and dynamic respond are analyzed. Finally, the relationship between energy density of the power sources and the endurance of the two UAVs is presented and analyzed. 


\section{Modeling of Propulsion system and Complete UAVs}

\section{Lithium-ion Battery Model}

Most of the energy from batteries is used to power the electric motor and actuate the onboard avionics. The endurance of UAVs is determined by the total energy of batteries. The discharge and charge characteristics of batteries are modeled by the following equations ${ }^{[5]}$ :

$$
\begin{gathered}
\text { Discharge }: E=E_{0}-R \cdot i-K \cdot \frac{Q}{Q-i t} \cdot(i *+i t)+A \cdot \exp (-B \cdot i t) \\
\text { Charge }: E=E_{0}-R \cdot i-K \cdot \frac{Q}{i t-0.1 \cdot Q} \cdot i *-K \cdot \frac{Q}{Q-i t} \cdot i t+A \cdot \exp (-B \cdot i t)
\end{gathered}
$$

where, $V_{\text {batt }}$ is battery voltage $(V) ; E_{0}$ represents battery constant voltage; $K$ is polarization constant (V/Ah); $Q$ is battery capacity $(A h) ; i t=\int i d t$ equals to actual battery charge; $A$ and $B$ are exponential zone amplitude $(V)$ and exponential zone time constant inverse $(A h)^{-1}$ respectively; $R$ is internal resistance $(\Omega) ; i$ and $i^{*}$ are battery current and filtered current respectively (A).

The state-of-charge (SOC) is used to present the Battery state, e.g. 100\% indicates the batteries are fully charged. The SOC is expressed by:

$$
S O C=1-\frac{1}{Q} \int_{0}^{t} i(t) d t
$$

When SOC is below $10 \%$, the batteries should stop discharging, in case they are destroyed. The energy subsystem contains a $13 \mathrm{~S}$ battery whose nominal voltage and capacity are $48.1 \mathrm{~V}$ and $18 \mathrm{Ah}$ respectively. Its maximum voltage is $54.6 \mathrm{~V}$, and the mass of the battery is $4.0 \mathrm{~kg}$ with the specific energy being almost $245 \mathrm{Wh} / \mathrm{kg}$. The parameters required by the model are shown in Fig. 1, along with simulation discharge curves for the battery system.

\begin{tabular}{|l|ll|}
\hline & \multicolumn{3}{|l|}{ Battery model input parameters } \\
\cline { 2 - 3 } & Nominal voltage (V) & 48 \\
Maximum capacity (Ah) & 18 \\
Fully charged voltage (V) & 55.87 \\
Nominal discharge current (A) & 17.39 \\
Internal resistance (Ohms) & 0.012 \\
Capacity at nominal voltage (Ah) & 14.17 \\
(a) & Exponential zone voltage (V) & 52.3 \\
& Exponential zone Current (A) & 1.96 \\
Energy density (Wh/kg) & 226 \\
Initial state-of-charge & 1 \\
Battery response time (s) & 20 \\
\hline
\end{tabular}

(b)
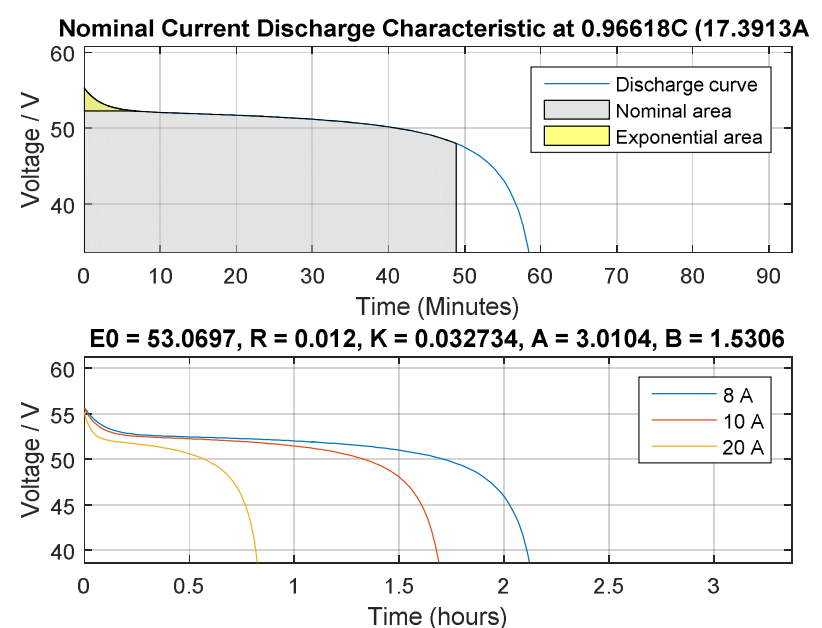

(c)

Fig. 1. Battery model. (a) Battery. (b) Input parameters. (c) Discharge curves.

\section{Hydrogen Fuel Cell Model}

The high energy density and conversion efficiency enable the fuel cell to support the longer mission endurance for UAVs. The fuel cell model for this paper are follows ${ }^{[2]}$, which gave the main equations as below:

$$
\begin{aligned}
& V_{f c}=E_{o c}-A \ln \left(\frac{i_{f c}}{i_{0}}\right) \frac{1}{s T_{d} / 3+1}-R_{o h m} i_{f c} \\
& V_{s t a c k}=N \cdot V_{f c}
\end{aligned}
$$

where, $E_{o c}$ is the open circuit voltage $(\mathrm{V})$ of fuel cell, $A$ is the slope of the Tafel line, $i_{0}$ is the exchange 
current (A), $R_{\text {ohm }}$ is the combined cell and diffusion resistance $(\Omega), T_{d}$ is the cell settling time to a current step, $i_{f c}$ is the fuel cell current (A), $V_{f c}$ is the voltage of every single cell (V), $N$ is the number of cells, $V_{\text {stack }}$ is the voltage of the fuel cell (V). In addition, the state of pressure (SOP) with interval [0, 1] represents the remainder hydrogen in storages. The equation of SOP is

$$
S O P=1-\frac{1}{V o l \cdot P_{0}} \int_{0}^{t} u(t) d t
$$

where, $P_{0}$ is the initial pressure of the hydrogen storage, Vol is the volume of the hydrogen storages, $u(t)$ is the flow rate of the hydrogen. When hydrogen pressure in storage is less than 10 bars, the fuel cell will stop work. The mass of the fuel cell is $4.0 \mathrm{~kg}$. Fig. 2 shows the model input parameters along with the simulated polarization curves.

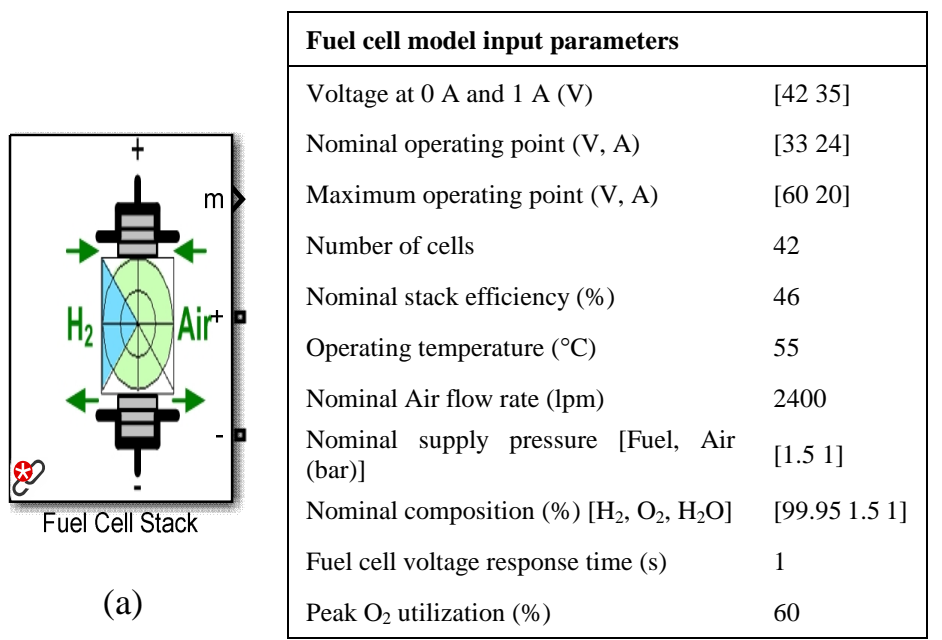

(b)
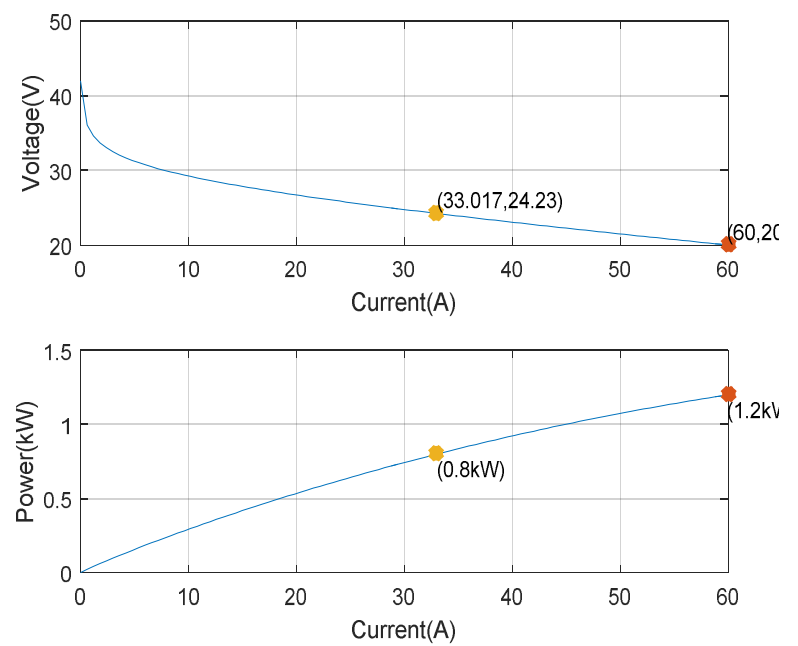

(c)

Fig. 2. Fuel cell stack model. (a) Fuel cell. (b) Input parameters. (c) Polarization curves.

\section{Motor Model}

This paper establishes a simplified electric motor model. The motor obtains the required power according to the throttle massage. The torque is determined by the equation(6).

$$
T_{\text {motor }}=P_{\text {motor }} / \omega
$$

where, $T_{\text {motor }}$ is the torque $(\mathrm{Nm}) ; P_{\text {motor }}$ represents the output power $(\mathrm{W}) ; \omega$ is the motor rotation rate $(\mathrm{rad} / \mathrm{s})$ which can be computed by using iterative procedure.

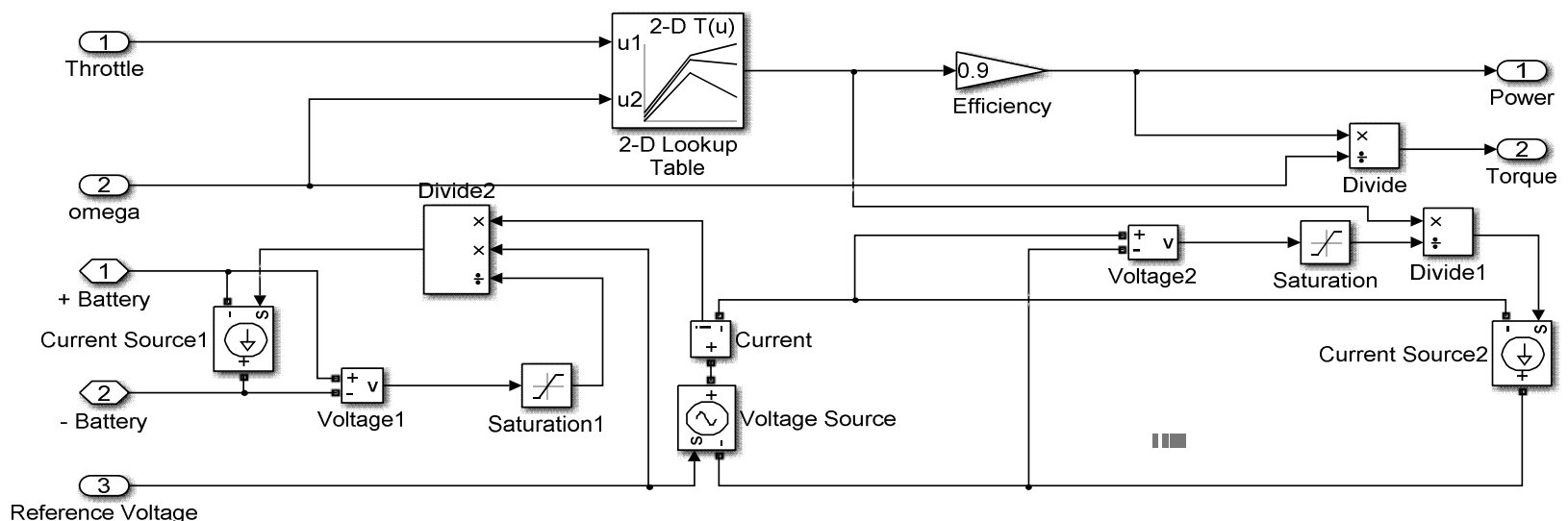

Fig. 3 Simplified electric motor model

Fig. 3 shows the simplified model of the electric motor. It is assumed that the efficiency of the motor is $90 \%$ and the calculated torque is directly applied on the motor shaft without any loss. By utilizing DC bus voltage and required power, the DC current can be calculated based on energy 
balance principle. In addition, using DC current, reference voltage and battery voltage, it's possible to compute the battery current.

\section{Propulsion System Model and Complete UAV Model}

The UAV accomplishes specific mission, e.g., investigation, surveillance, and reconnaissance. The UAV model is based on AeroSim Blockset which provides a comprehensive set of tools for development of non-linear 6-degrees-of-freedom (6-DOF) Aircraft model. The key parameters of the UAV are listed in Table 1.

Table 1 Basic parameters of UAV

\begin{tabular}{lccc}
\hline Parameter Name & Identifier & Value & Unit \\
\hline Aircraft mass & $M$ & 12.5 & $\mathrm{Kg}$ \\
Wing span & $B$ & 2.8956 & $\mathrm{~m}$ \\
Wing area & $S$ & 0.55 & $\mathrm{~m}^{2}$ \\
Mean aerodynamic chord & $M A C$ & 0.189941 & $\mathrm{~m}$ \\
\hline
\end{tabular}

The aircraft model mainly contains motion equation, dynamic equation, propulsion system and aerodynamic system etc. Especially, the internal-combustion engine (ICE) propulsion system in 6-DOF aircraft model was changed into the electric propulsion system, which is powered by Li-ion batteries or fuel cell, as Fig. 4 and Fig. 5 showing. The complete UAV model is shown in Fig. 6. The control subsystem includes navigation and autopilot modules. The drawing module is to show the path of the UAV.

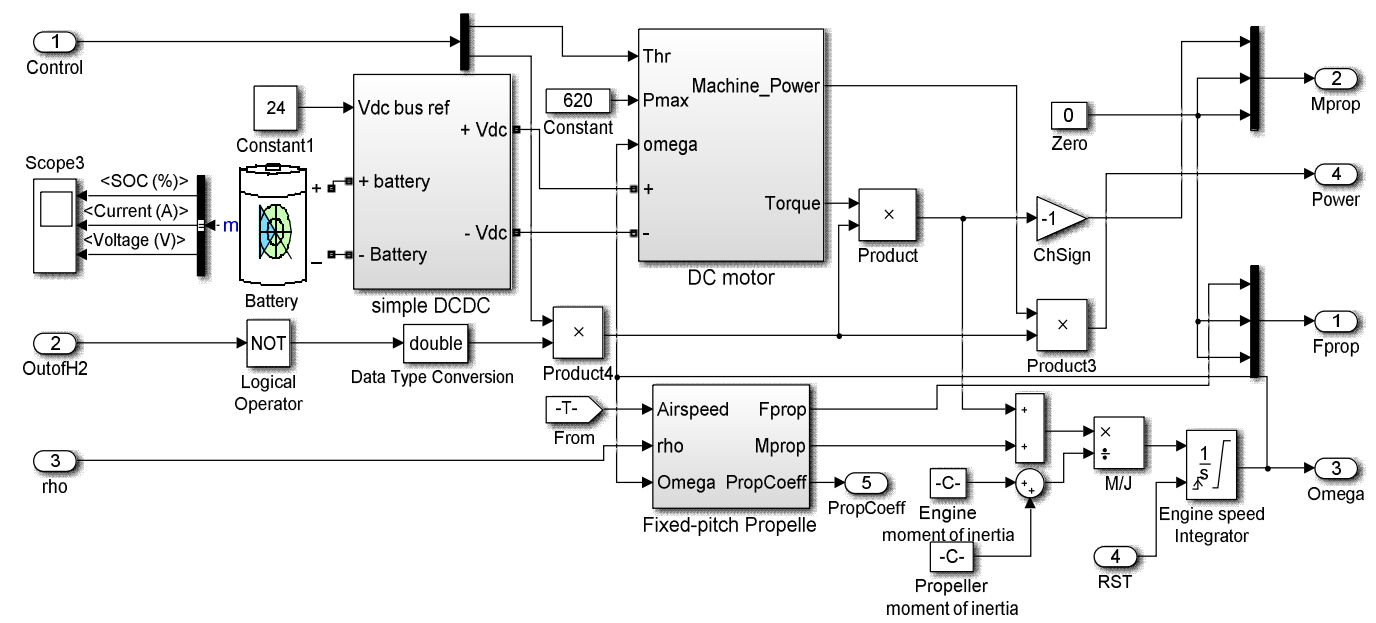

Fig. 4 The battery powered propulsion model

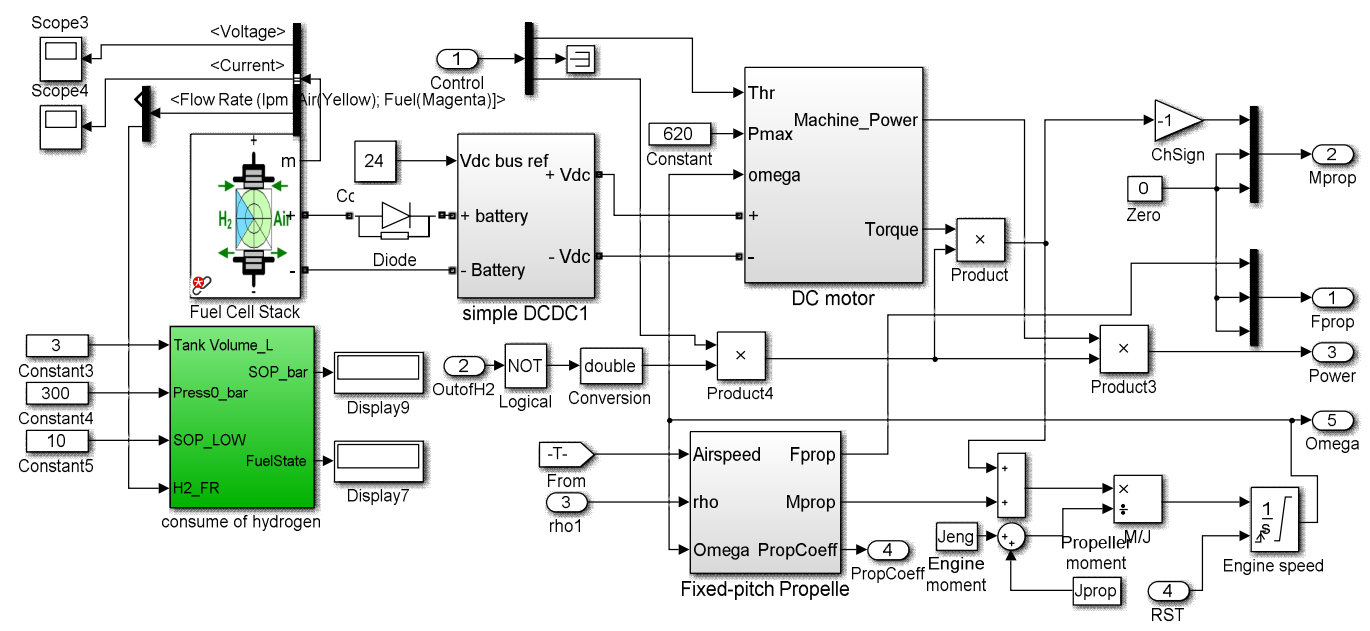

Fig. 5 The fuel cell powered propulsion model 


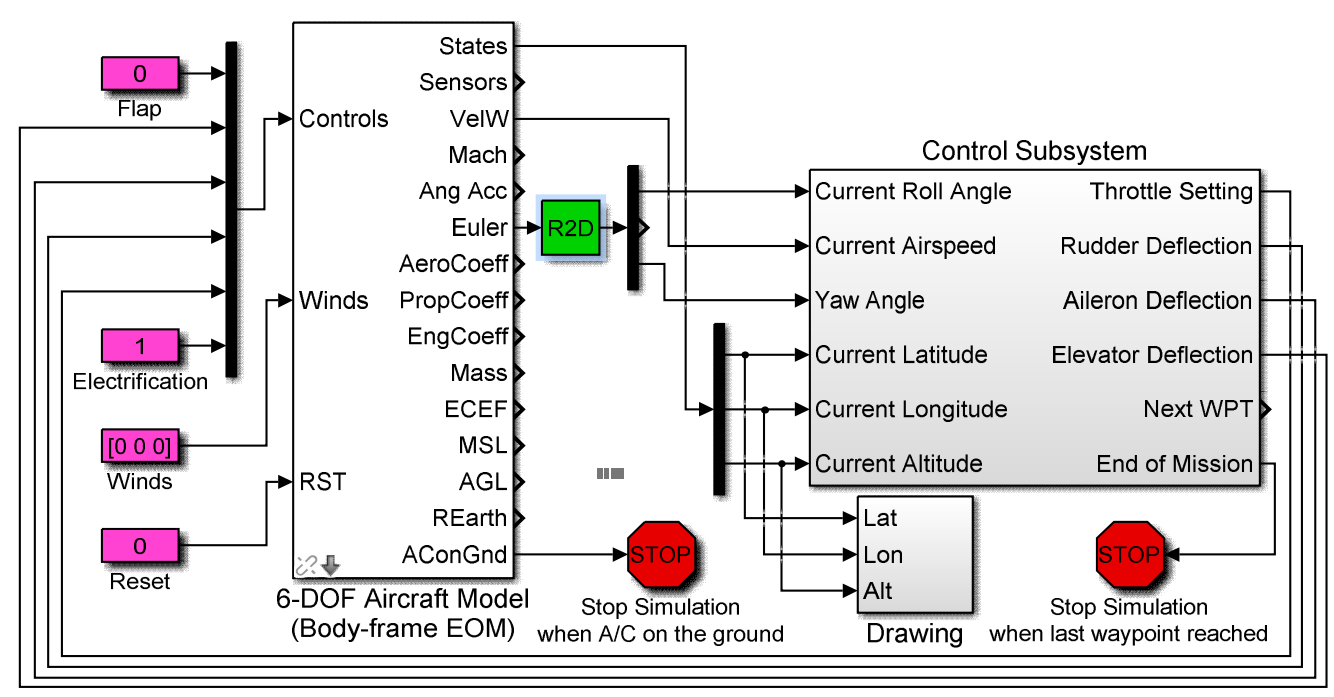

Fig. 6 The complete UAV model

\section{Simulation}

Table 2 shows mission waypoints information which is utilized to evaluate the electric powered UAV model. The information contains the position (latitude, longitude), altitude and velocity of the every waypoint (WP). Note from Table 2 that WP1 and WP5 have the same location and the airspeed is changing with different states, e.g., the descent speed is $30 \mathrm{~m} / \mathrm{s}$ and the climb velocity is $20 \mathrm{~m} / \mathrm{s}$.

Table 2 Waypoints in the mission flight path

\begin{tabular}{|c|c|c|c|c|}
\hline Waypoint & $\begin{array}{c}\text { Latitude } \\
\text { (DD: MM: SS) }\end{array}$ & $\begin{array}{c}\text { Longitude } \\
\text { (DD: MM: SS) }\end{array}$ & $\begin{array}{l}\text { Altitude } \\
\text { (m) }\end{array}$ & $\begin{array}{c}\text { Velocity } \\
(\mathrm{m} / \mathrm{s})\end{array}$ \\
\hline WP1 (Origin) & $26^{\circ} 34^{\prime} 51^{\prime \prime} \mathrm{N}$ & $151^{\circ} 50^{\prime} 28^{\prime \prime} \mathrm{E}$ & 800 & 20 \\
\hline WP2 & $26^{\circ} 35^{\prime} 10^{\prime \prime} \mathrm{N}$ & $151^{\circ} 52^{\prime} 40^{\prime \prime} \mathrm{E}$ & 900 & 20 \\
\hline WP3 & $26^{\circ} 34^{\prime} 16^{\prime \prime} \mathrm{N}$ & $151^{\circ} 53^{\prime} 23^{\prime \prime} \mathrm{E}$ & 800 & 30 \\
\hline WP4 & $26^{\circ} 33^{\prime} 50^{\prime \prime} \mathrm{N}$ & $151^{\circ} 51^{\prime} 18^{\prime \prime} \mathrm{E}$ & 900 & 20 \\
\hline WP5 (End point) & $26^{\circ} 34^{\prime} 51^{\prime \prime} \mathrm{N}$ & $151^{\circ} 50^{\prime} 28^{\prime \prime} \mathrm{E}$ & 800 & 30 \\
\hline
\end{tabular}

Use the same mission waypoints to valid the batteries powered UAV and the fuel cell powered UAV. The results of the two electric UAVs flight simulation are shown in Fig. 7 (a) and Fig. 7 (b). The flight path of batteries powered UAV almost coincides with that of the fuel cell powered UAV. The flight path shows that the both of them success tracking the waypoints with smooth path. Note from the Figure 8 that these two UAVs accomplished the course of clime, cruise, turning, and descent quite well. Additionally, there is no stall in the process of simulation.

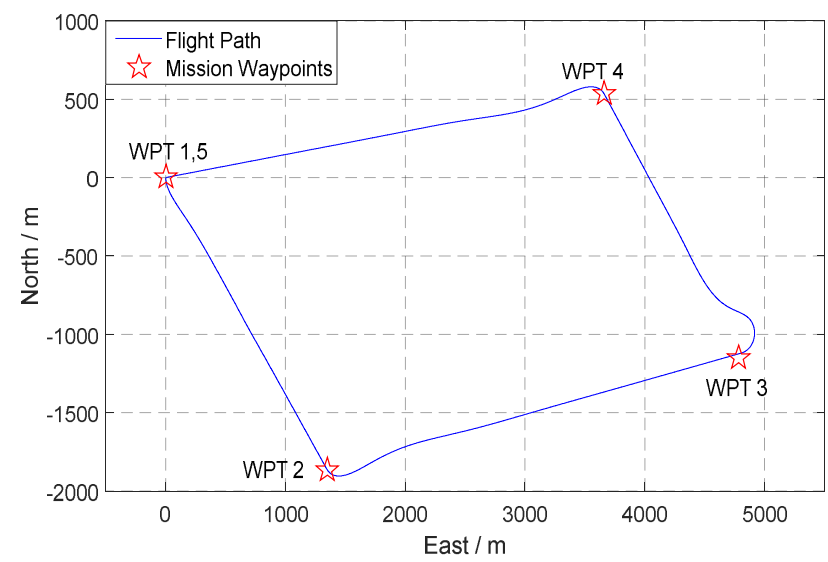

(a) Top view of the flight path

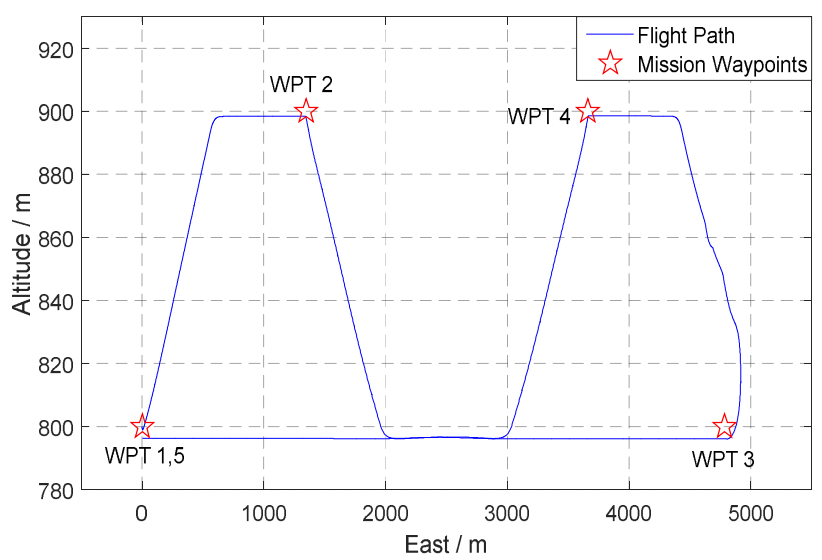

(b) Side view of the flight path

Fig. 7 Test results - View of flight path 
In addition, the control surface deflections (aileron, elevator and rudder) shown in Fig. 8 (a) are used to control the attitude of the UAV. The surface deflections have big fluctuations in the middle of simulation when the aircraft is turning. From Fig. 8 (b), we can see that the bank angle is within the interval $\left[-33.8^{\circ}, 5.8^{\circ}\right]$, the pitch angle is within $\left[-7.4^{\circ}, 16.5^{\circ}\right]$, and the variation range of the yaw angle is within $\left[0^{\circ}, 360^{\circ}\right]$. They are all reasonable, so the battery and fuel cell powered UAV models are validity and availability.

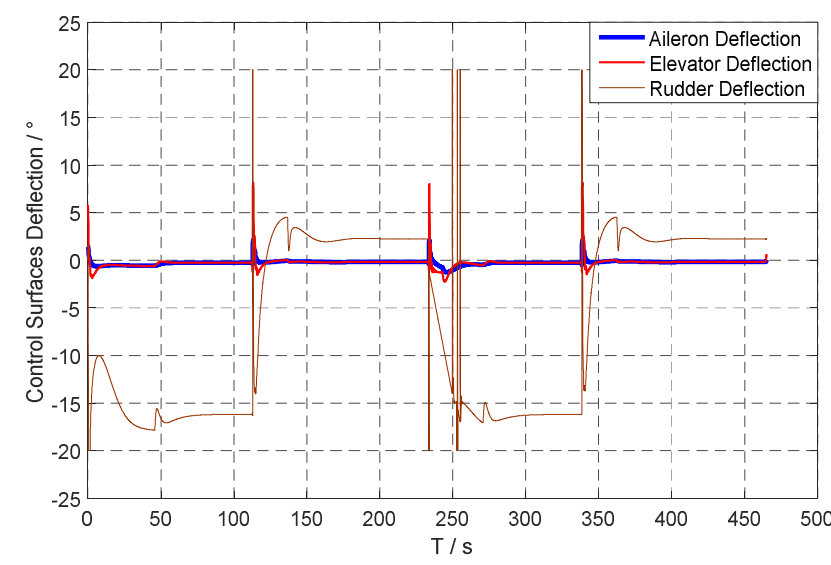

(a) The control surfaces deflection

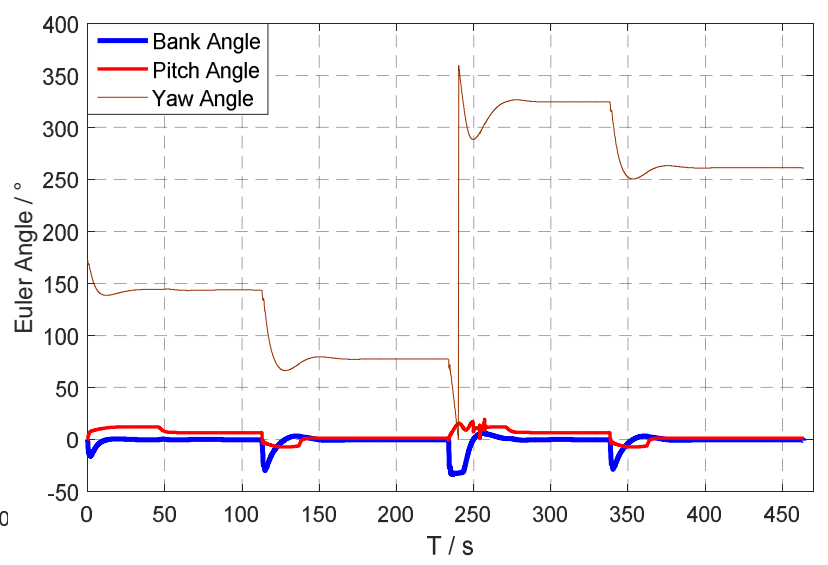

(b) The Euler angle

Fig. 8 The control surfaces deflection and Euler angle varing with time

\section{Performance Analysis}

\section{Endurance}

The endurance of battery powered UAV and fuel cell powered UAV are determined by the SOC and SOP respectively. Fig. 9 (a) and Fig. 9 (b) present the SOC of batteries and the SOP of Hydrogen in the storage to support the UAV to fly as long as possible. Initially, the UAVs climb to waypoint 2 with high power, so that the descent gradients of SOC and SOP are relatively large. According to section 2, the weights of battery powered UAV and fuel cell powered UAV are the same. Both the initial states of the SOC and SOP are 100\%. For the battery powered UAV, if the SOC is below $10 \%$, then the simulation is stop. And for the fuel powered UAV, the stop condition of the simulation is less than 10 bar hydrogen left in the storage. Based on the conditions and the simulation results above, the endurance of the battery powered UAV is $2.5 \mathrm{~h}$ and the endurance of the fuel cell powered UAV is 4.7 $\mathrm{h}$. Because the hydrogen weight is less than $1 \%$ of the whole fuel cell UAV, so the change of UAV weight can be ignored.

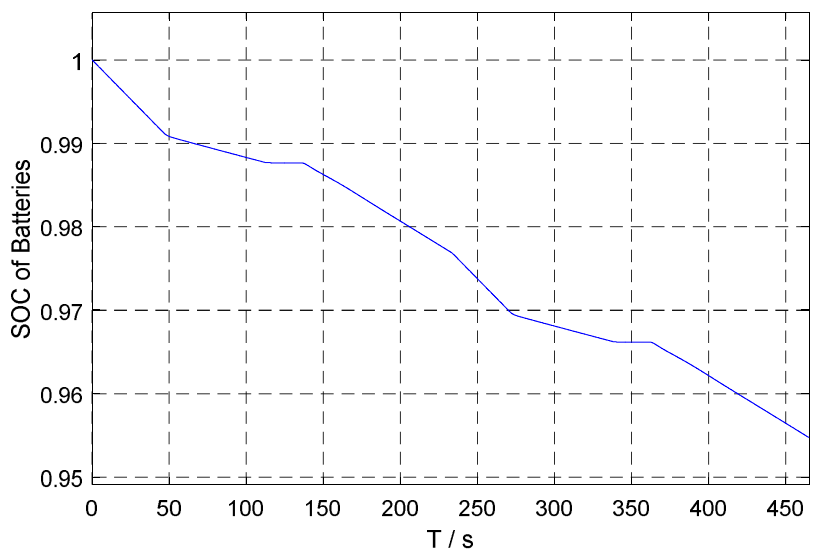

(a) SOC - time curve

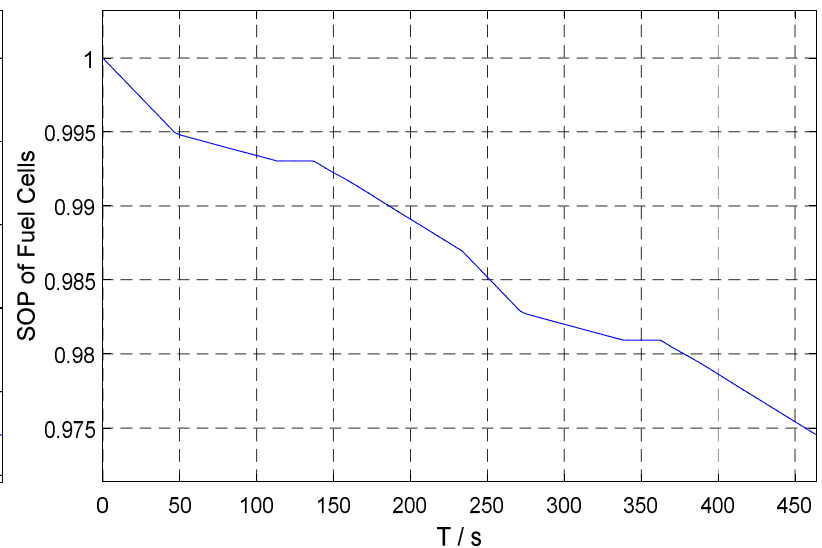

(b) SOP - time curve

Fig. 9 SOC of the battery and SOP of the fuel cell varing with time

\section{Dynamic Respond of Batteries and Fuel Cells}

During a whole circle of the flight path, the voltage and current of the battery or fuel cell are shown in Fig. 10 (a) and Fig. 10 (b). For the battery with the load changing, the voltage changes within 52.02 
$\mathrm{V}$ to $52.32 \mathrm{~V}$, less than $0.6 \%$. Due to the battery energy consumption, the voltage is declining from full charge voltage to nominal voltage. As the Fig. 10 (a) showing, the second peak voltage value is less than the first one. The peak current is $12.2 \mathrm{~A}$, while the output power is $610 \mathrm{~W}$.

The voltage of the fuel cell changes from $25.8 \mathrm{~V}$ to $38.0 \mathrm{~V}$. The variation is about $37 \%$ of the nominal voltage. So compared with battery's, the characteristics of the fuel cell is softer. During climbing, the demand power is highest, the voltage of the fuel cell is lowest and the current is highest. However, in descent stages, the voltage is the highest and the current is zero. The dynamic response of fuel cell is rapid enough to accomplish the smooth turning.

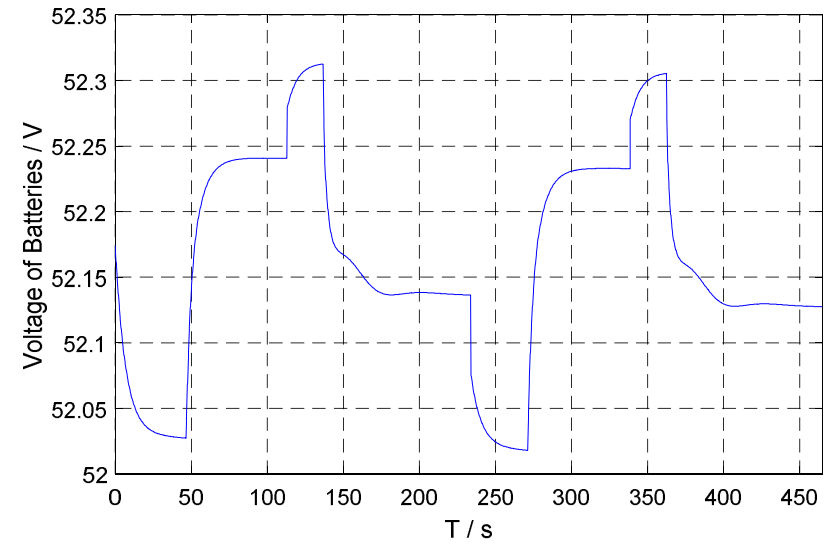

(a) Voltage - time curve

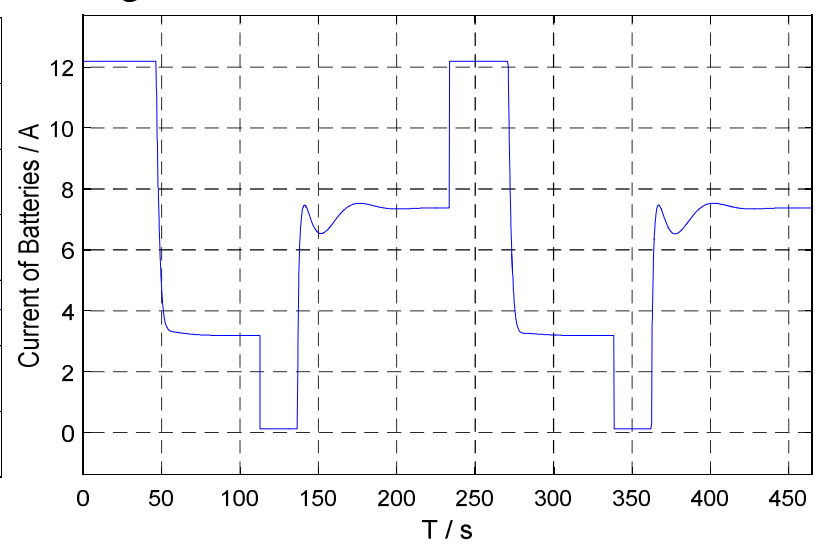

(b) Current - time curve

Fig. 10 The voltage and current of the battery varing with time

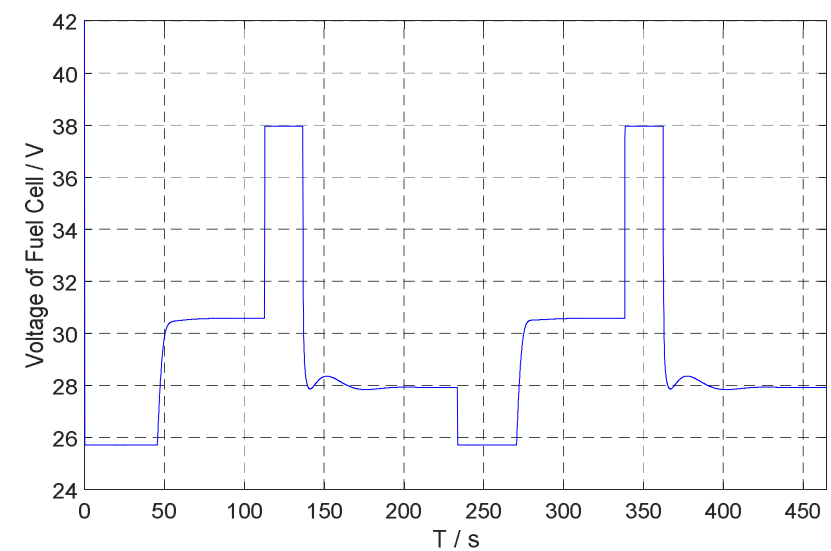

(a) Voltage - time curve

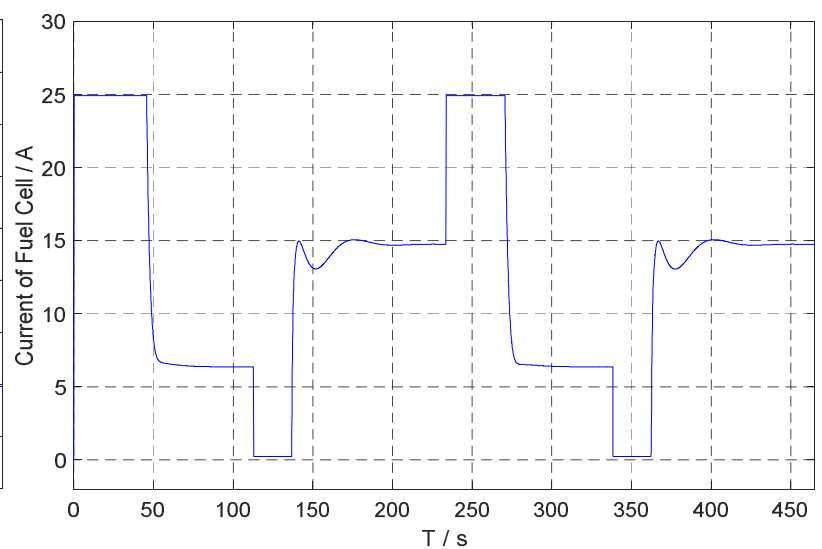

(b) Current - time curve

Fig. 11 The voltage and current of the fuel cell varing with time

Referring to Fig. 12 (a) and Fig. 12 (b), note that when the UAV is climbing, the propulsion system provides plenteous power approximate $675 \mathrm{~W}$. Besides, the cruise power at $20 \mathrm{~m} / \mathrm{s}$ and $30 \mathrm{~m} / \mathrm{s}$ approaches $200 \mathrm{~W}$ and $410 \mathrm{~W}$ respectively.

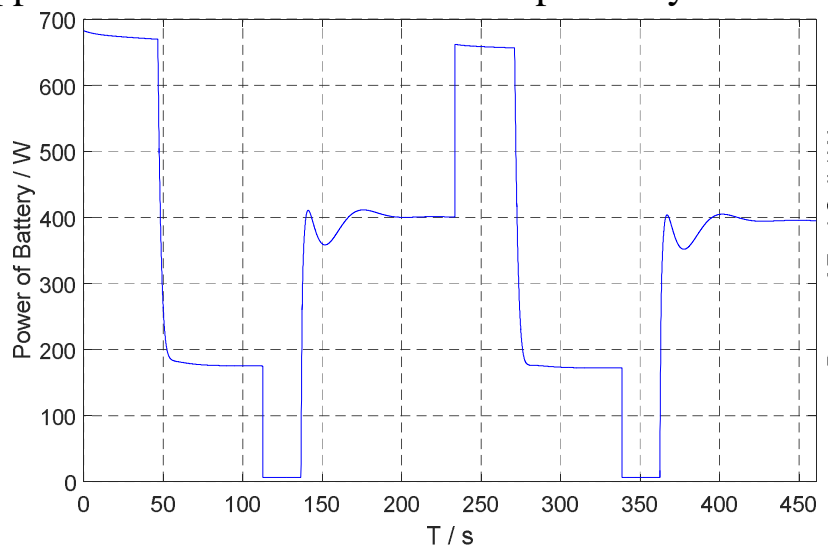

(a) Power - time curve of the battery

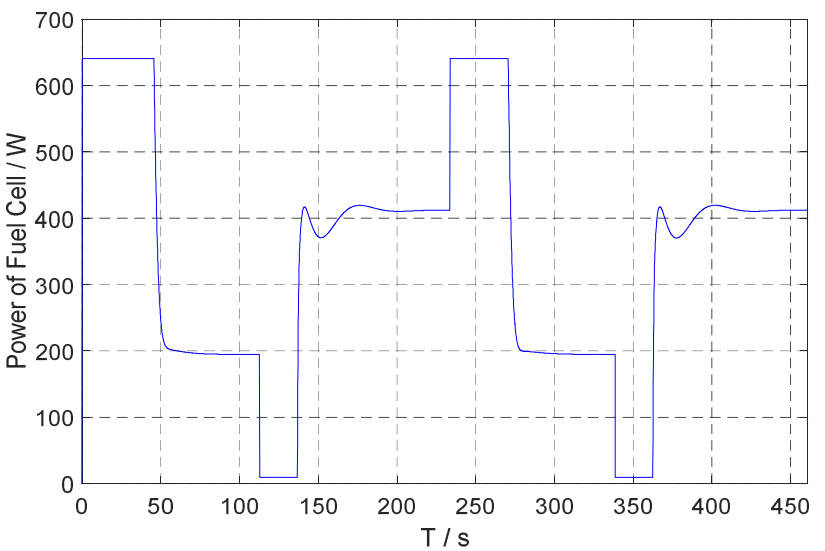

(b) Power - time curve of the fuel cell

Fig. 12 The power of the battery and the fuel cell varing with time 


\section{Conclusions}

This paper establishes two low altitude electric UAV models powered by the battery or fuel cell. The two electric UAVs have the same weight $(12.5 \mathrm{~kg})$. A diamond-shaped mission path is used to evaluation and performance analysis of these models. The results illustrate that these two UAVs are valid to track the waypoints both horizontally and vertically. What's more, the dynamic response of power is rapid enough to accomplish smooth turning. The endurance of the battery powered UAV is less than the fuel cell powered UAV with the same weight. To overcome the shortage of the batteries and fuel cells, a hybrid system which a fuel cell is combined with a battery, can be established to enhance the endurance of the UAV as the future work.

\section{References}

[1] Des Verstra, AndGong, DylanD.-C. Lu, Jennifer L.Palmer. Experimental Investigation of the Role of the Battery in the Aerostack Brid, Fuel-Cell-Based Propulsion System for Small Unmanned Aircraft Systems. International Journal of Hydrogen Energy 2015, Vol. 40 (2015), p. 1598-1606.

[2] Yanping Li, Li Liu, Xingwei Ma and Haifeng Tu. Design of Hybrid Electric Propulsion System for Long Endurance Small UAVs. 10th International Energy Conversion Engineering Conference. Atlanta, Georgia, 2012.

[3] John Wang, Ping Liu, Jocelyn Hicks-Garner, Elena Sherman, Souren Soukiazian. Cycle-Life Model for Graphite-LiFePO4 Cells. Journal of Power Source 2011, Vol. 196 (2011), p. 3942-3948.

[4] D. Verstraete, K. Lehmkuehler, A. Gong, J.R. Harvey, G. Brain, J.L. Palmer. Characterisation of a Hybrid, Fuel-Cell-Based Propulsion System for Small Unmanned Aircraft. Journal of Power Source 2014, Vol. 250 (2014), p. 204-211.

[5] Olivier Tremblay, Louis-A, Dessaint. Experimental Validation of a Battery Dynamic Model for Ev Applications. World Electric Vehicle Journal 2009, Vol. 3 (2032-6653), p. 1-10.

[6] Open-Cathode PEM Fuel Cell. http:// www.horizonfuelcell.com.

[7] Jane Yu-Chun Hung. Investigation of Methods for Increasing the Energy Efficiency on Unmanned Arrial Vehicles (Uavs). Queensland University of Technology, 2011.

[8] Jane Yu-Chun Hung and Luis Felipe Gonzalez. On Parallel Hybrid-Electric Propulsion System for Unmanned Aerial Vehicles. Progress in Aerospace Sciences 2012, Vol. 51 (2012), p. 1-17.

[9] Peter Lindahl, Eric Moog and Steven R. Shaw. Simulation, Design, and Validation of an UAV SOFC Propulsion System. IEEE Transavtions on Aerospace and Electric Systems 2012, Vol. 48 (3), p. 2582-2593. 